\title{
NOTES
}

\section{Polymerization of Macromonomers IV. Monomer Reactivity Ratios in Radical Copolymerization of Methyl Methacrylate with ( $p$-Vinylbenzyl)polystyrene Macromonomer}

\author{
Mikio TAKAKI, Ryuzo ASAMI, and Takashi MATSUSE \\ Department of Applied Chemistry, Nagoya Institute of Technology, \\ Gokiso-cho, Showa-ku, Nagoya 466, Japan
}

(Received December 13, 1988)

\begin{abstract}
KEY WORDS Monomer Reactivity Ratio / ( $p$-Vinylbenzyl)polystyrene / Methyl Methacrylate / ${ }^{13} \mathrm{C}$-Enriched Methyl Methacrylate / Radical Copolymerization / Polymer Effect / Concept of Equal Reactivity /
\end{abstract}

Macromonomers have been recognized to be extremely useful for the preparation of novel multibranched (co-)polymers such as star, comb, and graft type (co-)polymers, as reviewed by many polymer chemists. ${ }^{1}$

For the construction of well-defined polymer architecture by such a macromonomer, fundamental data on homo- and/or copolymerization of the macromonomer are indispensable. In regard to copolymerizations of conventional small monomers $\left(\mathrm{M}_{1}\right)$ with macromonomers $\left(\mathrm{M}_{2}\right)$, monomer reactivity ratios of $r_{1}$ have been reported relatively extensively. ${ }^{2-12}$ However, papers dealing with both $r_{1}$ and $r_{2}$ values have been limited. ${ }^{13-18}$

We previously ${ }^{19}$ determined both $r_{1}$ and $r_{2}$ for a combination of 2-vinylnaphthalene and methacrylate-/acrylate-terminated poly(tetrahydrofuran) macromonomers using large difference in their extinction coefficients in the UV range.

In the present study, we evaluated both $r_{1}$ and $r_{2}$ values in the copolymerization of methyl methacrylate $\left(\mathrm{M}_{1}\right)$ with ( $p$-vinylbenzyl)polystyrene macromonomer $\left(\mathrm{M}_{2}\right)$, by taking advantage of the high sensitivity of the carbonyl group of the small monomer to an IR spectrometer.

\section{EXPERIMENTAL}

Materials, Procedures, and Measurements

Two different molecular weights of VB-PSt macromonomers were prepared by a method reported previously. ${ }^{20}$ The characterization results of the macromonomers are as follows.

$$
\begin{aligned}
& \text { VB-PSt }{ }_{3}: M_{n}=3.0 \times 10^{3}, \\
& M_{w} / M_{n}=1.1_{7}, \quad f=1.0 \\
& \text { VB-PSt }_{6}: M_{n}=6.2 \times 10^{3}, \\
& M_{w} / M_{n}=1.0_{5}, \quad f=0.97
\end{aligned}
$$

${ }^{13} \mathrm{C}$-Enriched MMA was synthesized from ${ }^{13} \mathrm{C}$ $\mathrm{CH}_{3} \mathrm{OH}$ and methacryloyl chloride. The purity and ${ }^{13} \mathrm{C}$-content of the monomer obtained after the fractional distillation were $88.2 \%$ and $22.3 \%$, respectively. Commercially available MMA and $\alpha, \alpha^{\prime}$-azobisisobutyronitrile (AIBN) were purified by the usual methods.

The procedures for the copolymerization of MMA with VB-PSt were the same as in the previous paper. ${ }^{19}$

Infrared (IR) spectra were recorded at a sufficiently slow scanning speed $(20 \mathrm{~min})$ for quantitative purposes on a JASCO A-102 spectrometer. ${ }^{13} \mathrm{C}$ NMR measurements were carried out in deuterochloroform solutions on 
a Varian XL-200 spectrometer operated at $50 \mathrm{MHz}$. Gel permeation chromatographic (GPC) analysis was performed as reported previously. ${ }^{19}$

\section{Determination of Composition of Copolymer}

Owing to the narrow molecular weight distribution of VB-PSt, a GPC curve of recovered polymer after copolymerization gave good separation between the peaks of copolymer and unpolymerized VB-PSt. Thus, the extent of conversion of VB-PSt could be readily determined by the ratio of the area of the copolymer peak to the total response, because the contribution of the PMMA moiety to the copolymer peak area was negligibly small.

The extent of conversion of the small monomers was mainly determined by an IR method. The method was based on a calibration curve constructed by plotting the transmittance ratios of $1730 \mathrm{~cm}^{-1}(\mathrm{C}=\mathrm{O})$ to 1875 $\mathrm{cm}^{-1}$ (benzene ring) against the mole ratios of PMMA monomer units to PSt monomer units. Some values determined by the IR method were checked by a ${ }^{13} \mathrm{C}$ NMR method involving a calibration curve. The curve was obtained by plotting the peak intensity ratios of methoxy carbons of ${ }^{13} \mathrm{C}$-enriched MMA to the 1-carbons of benzene rings of polystyrene units against the mole ratios of PMMA monomer units to PSt monomer units.

The compositions of the copolymers were determined from the extents of both conversion of VB-PSt and small monomers determined according to the above method.

\section{RESULTS AND DISCUSSION}

\section{Radical Copolymerization of VB-PSt Macro- monomer}

Typical results of the copolymerizations are summarized in Table I along with copolymerization conditions. The copolymer composition data by the IR method are consistent with those by the ${ }^{13} \mathrm{C}$ NMR method within experimental error. Figure 1 shows plots of monomer feed vs. copolymer composition and copolymerization composition curves drawn from the monomer reactivity ratios estimated by the intersection method. The experimental points are in fair agreement with the copolymer composition curves, supporting the validity of the values of monomer reactivity ratios. Also, Figure 1 illustrates the copolymerization reactivity of VB-PSt to decrease

Table I. Radical copolymerization of MMA $\left(\mathrm{M}_{1}\right)$ with VB-PSt $\left(\mathrm{M}_{2}\right)^{\mathrm{a}}$

\begin{tabular}{|c|c|c|c|c|c|c|c|}
\hline \multirow[t]{2}{*}{ Run } & \multirow{2}{*}{$\frac{M_{1}}{m g}$} & \multirow{2}{*}{$\frac{\mathrm{M}_{2}}{\mathrm{mg}}$} & \multirow{2}{*}{$\frac{\text { Benzene }}{\mathrm{mg}}$} & \multirow{2}{*}{$\frac{\text { Time }}{h}$} & \multirow{2}{*}{$\frac{\text { Conv. }}{\%}$} & \multicolumn{2}{|c|}{$\begin{array}{c}\mathrm{Mol}_{\%}^{\%} \text { of } \mathrm{M}_{2} \\
\text { in }\end{array}$} \\
\hline & & & & & & feed & copolymer \\
\hline & MMA & VB-PSt ${ }_{6}$ & & & & & \\
\hline 1 & 21.7 & 151 & 254 & 0.3 & 17 & 10 & $13^{\mathrm{c}}$ \\
\hline 2 & 3.8 & 154 & 275 & 1.5 & 30 & 39 & $33^{\mathrm{c}}$ \\
\hline 3 & 2.1 & 184 & 340 & 2.5 & 20 & 59 & $46^{\mathrm{c}}$ \\
\hline 4 & 0.5 & 251 & 480 & 5.0 & 19 & 89 & $83^{c}$ \\
\hline & ${ }^{13} \mathrm{CMMA}^{\mathrm{b}}$ & $\mathrm{VB}-\mathrm{PSt}_{3}$ & & & & & \\
\hline 5 & 45.1 & 150 & 671 & 0.3 & 14 & 10 & $18^{\mathrm{c}}$ \\
\hline 6 & 15.2 & 150 & 704 & 0.7 & 15 & 25 & $30^{c}(25)^{d}$ \\
\hline 7 & 4.4 & 149 & 706 & 2.0 & 15 & 53 & $46^{c}(43)^{d}$ \\
\hline 8 & 3.0 & 201 & 951 & 2.5 & 15 & 69 & $66^{c}(62)^{d}$ \\
\hline
\end{tabular}

${ }^{a}$ Copolymerization conditions: temp, $60^{\circ} \mathrm{C}$; solvent, benzene; $\left[\mathrm{M}_{2}\right]_{0} \approx 50 \mathrm{mmol} \mathrm{l}^{-1}$; $[\mathrm{AIBN}]_{0} \approx 20 \mathrm{mmol}^{-1}$.

b ${ }^{13}$ C-enriched MMA.

c Determined by the IR method.

${ }^{d}$ Determined by the ${ }^{13} \mathrm{C}$ NMR method. 
slightly with increase in the molecular weight of VB-PSt. These findings will be discussed in the following section.

\section{Monomer Reactivity Ratio}

Monomer reactivity ratios for the copolymerizations of MMA $\left(\mathrm{M}_{1}\right)$ with VB-PSt's $\left(\mathrm{M}_{2}\right)$ were estimated by both intersection and Fineman-Ross methods. The values are listed in Table II together with the literature values of monomer reactivity ratios in copolymerizations of MMA $\left(M_{1}\right)$ with styrene ${ }^{21}$ and with $p$-methylstyrene ${ }^{22}\left(\mathrm{M}_{2}\right)$ which can be regarded as model copolymerizations. In the copolymerization of VB-PSt having molecular weight of $6.2 \times 10^{3}$, the value of $r_{1}$ was about twice as large as that of the model copolymerizations, whereas the $r_{2}$ value was around half as small as that of the model copolymerizations. In the case of VB-PSt with molecular

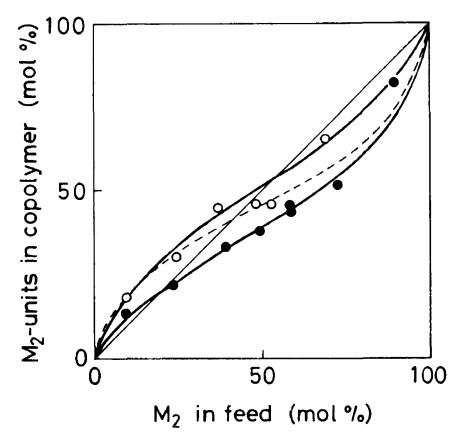

Figure 1. Copolymer composition curves for copolymerizations of MMA $\left(M_{1}\right)$ with $M_{2}$ by AIBN at $60 \mathrm{C}$ in benzene. $\mathrm{M}_{2}=$ VB-PSt ${ }_{6}(-\mathrm{O}-)$, VB-PSt ${ }_{3}(-\mathrm{O}-)$, or St (---). weight of $3.0 \times 10^{3}$, however, the value of $r_{1}$ was close to that of the model copolymerization while the $r_{2}$ value was similar to that in the case of VB-PSt with molecular weight of $6.2 \times 10^{3}$. These results may be interpreted in terms of polymer effect $\mathrm{t}^{23-27}$ and the concept $\mathrm{t}^{28}$ of equal reactivity of growing chains, as described in the previous paper. ${ }^{19}$

In the monomer reactivity ratios, $r_{1}=k_{11} /$ $k_{12}$ and $r_{2}=k_{22} / k_{21}$, the rate constants for propagation reactions to low molecular weight monomer (i.e., $k_{11}$ and $k_{21}$ ) may be close to those for the model copolymerizations, because the concept of equal reactivity of growing chains is considered valid. On the other hand, the rate constants for propagation reactions to the macromonomer (i.e., $k_{12}$ and $k_{22}$ ) appear much lower than those for the model copolymerizations, because these propagations are concerned with polymer-polymer reactions. In reactions between polymers, it has been reported that the reaction rates are usually lower than those for an analogous small molecule reaction. For example, in anionic grafting reaction between polymers, hindering effect (kinetic excluded volume effect $^{27}$ ) on reaction rates was observed for middle pendant functional groups of backbone polymer more significantly than those located near at chain ends. ${ }^{25.26}$ In some cases $^{23,24}$ of bimolecular radical chain termination, the rate constant decreased by a factor of 100 or more. We recently found that star type and pine needle-shaped macromonomers,

Table II. Monomer reactivity ratio for the copolymerization of MMA with VB-PSt

\begin{tabular}{|c|c|c|c|c|c|c|}
\hline \multirow{2}{*}{$\mathrm{M}_{1}$} & \multicolumn{2}{|c|}{$\mathbf{M}_{2}$} & \multirow{2}{*}{$r_{1}$} & \multirow{2}{*}{$1 / r_{1}$} & \multirow{2}{*}{$r_{2}$} & \multirow{2}{*}{ Remarks } \\
\hline & & wt. $\times 10^{-3}$ & & & & \\
\hline MMA & VB-PSt & 6.2 & $0.89(0.76)^{\mathrm{a}}$ & $1.1(1.3)^{\mathrm{a}}$ & $0.22(0.14)^{\mathrm{a}}$ & This work \\
\hline${ }^{13} \mathrm{CMMA}^{\mathrm{b}}$ & VB-PSt & 3.0 & $0.47(0.44)^{\mathrm{a}}$ & $2.1(2.3)^{\mathrm{a}}$ & $0.24(0.18)^{\mathrm{a}}$ & This work \\
\hline MMA & $p$-MSt & 0.118 & 0.41 & 2.5 & 0.44 & $\operatorname{Ref} 23$ \\
\hline MMA & St & 0.104 & 0.46 & 2.2 & 0.52 & Ref 22 \\
\hline
\end{tabular}

a By the Fineman-Ross method.

b ${ }^{13}$ C-enriched MMA. 
which have a functional group at the center of a polymer chain, are hardly homopolymerized by a radical initiator. ${ }^{29}$ These findings on polymer effects on reaction rate suggest that the values of $k_{22}$ and $k_{12}$ for the copolymerization of VB-PSt are lower than those for the model copolymerization and that the extent of decrease in $k_{22}$ is higher than that in $k_{12}$ since $k_{22}$ involves an $\alpha$-branched polymer radical and a macromonomer molecule as reactants. The $\alpha$-branch directly attached to a unit of a growing radical would cause the position of the growing radical to be in the middle of the polymer chain.

Consequently, the $k_{22} / k_{21}\left(r_{2}\right)$ value for copolymerization of VB-PSt should be lower than that for the model copolymerization, whereas the $k_{11} / k_{12}\left(r_{1}\right)$ value for the copolymerization of VB-PSt should be higher than that for the model copolymerization. In the case of VB-PSt ${ }_{3}$, the $r_{1}$ value was almost comparable to that for the model copolymerization. This may be due to the slight hindering effect on the rate constant of $k_{12}$ by a branch relatively short and the lower viscosity of copolymerization solutions of $\mathrm{VB}-\mathrm{PSt}_{3}$ than that of VB-PSt ${ }_{6}$ solutions. The effect of viscosity has recently been found on the rate of macromonomer polymerization. ${ }^{30}$

\section{REFERENCES}

1. For very recent examples, Y. Kawakami, Kobunshi, 37, 264 (1988); Encyc. Polym. Sci. Eng., 9, 195 (1987).

2. S. Yamashita, K. Shibatani, K. Takakura, and K. Imai, Kobunshi Ronbunshu, 39, 187 (1982).

3. K. Ito, Y. Masuda, T. Shintani, T. Kitano, and Y. Yamashita, Polym. J., 15, 443 (1983).

4. J. P. Kennedy and M. Hiza, J. Polym. Sci., Polym. Ed., 21, 1033 (1983).

5. T. Fukutomi, A. Yokota, and K. Ishizu, J. Polym. Sci., Polym. Chem. Ed., 22, 2983 (1984).

6. G. O. Schulz and R. Milkovich, J. Polym. Sci. Polym. Chem. Ed., 22, 1633 (1984).

7. F. Severini, M. Pegerare, and L. Saija, Angew.
Makromol. Chem., 133, 111 (1985).

8. J. P. Kennedy and C. Y. Lo, Polym. Bull., 13, 343 (1985).

9. K. Ito, H. Tsuchida, A. Hayashi, T. Kitano, E. Yamada, and T. Matsumoto, Polym. J., 17, 761 (1985).

10. G. G. Cameron and M. S. Chisholm, Polymer, 26, 437 (1985); ibid., 27, 1420 (1986).

11. K. Ito, H. Tsuchida, and T. Kitano, Polym. Bull., 15, 425 (1986).

12. Y. Tsukahara, M. Tanaka, and Y. Yamashita, Polym. J., 19, 1121 (1987).

13. M. Niwa, T. Hayashi, and M. Akahori, J. Macromol. Sci.-Chem., A, 24, 49 (1987).

14. K. Mühlbach and V. Percec, J. Polym. Sci., Polym. Chem. Ed., 25, 2605 (1987).

15. K. Ito, N. Usami, and Y. Yamashita, Macromolecules, 13, 216 (1980).

16. R. Asami, M. Takaki, and T. Matsuse, Preprints, 1st SPSJ IPC, Kyoto, 1984, p. 76.

17. A. Revillon and T. Hamaide, Polym.Bull., 6, 235 (1982).

18. K. Ito, H. Tsuchida, A. Hayashi, T. Kitano, E. Yamada, and T. Matsumoto, Polym. J., 17, 827 (1985).

19. R. Asami, M. Takaki, and T. Matsuse, Makromol. Chem., in press.

20. R. Asami, M. Takaki, and H. Hanahata, Macromolecules, 16, 628 (1983).

21. F. M. Lewis, C. Walling, W. Cummings, E. R. Briggs, and W. J. Wenisch, J. Am. Chem. Soc., 70, 1519 (1948).

22. C. Walling, E. R. Briggs, K. B. Wolfstirn, and F. R. Mayo, J. Am. Chem. Soc., 70, 1537 (1948).

23. M. S. Matheson, E. E. Auer, E. B. Bevilacqua, and E. J. Hart, J. Am. Chem. Soc., 71, 497 (1949).

24. M. S. Matheson, E. E. Auer, E. B. Bevilacqua, and E. J. Hart, J. Am. Chem. Soc., 73, 1700 (1951); ibid., 73, 5395 (1951).

25. K. Ishizu, T. Fukutomi, T. Kakurai, and T. Noguchi, Polym. J., 4, 105 (1973).

26. K. Ishizu, T. Fukutomi, T. Kakurai, and T. Noguchi, Makromol. Chem., 179, 1981 (1978).

27. R. Morawetz, "Macromolecules in Solution," Interscience Publishers, New York, N.Y., 1965, Chapter 3.

28. P. J. Flory, "Principles of Polymer Chemistry," Cornell University Press, Ithaca, N.Y., 1953, Chapter 3.

29. R. Asami, K. Maeda, K. Nakamura, Polym. Prepr., 29(2), 19 (1988).

30. M. Takaki and R. Asami, Polym. Prepr. Jpn., 36, 1715 (1988). 